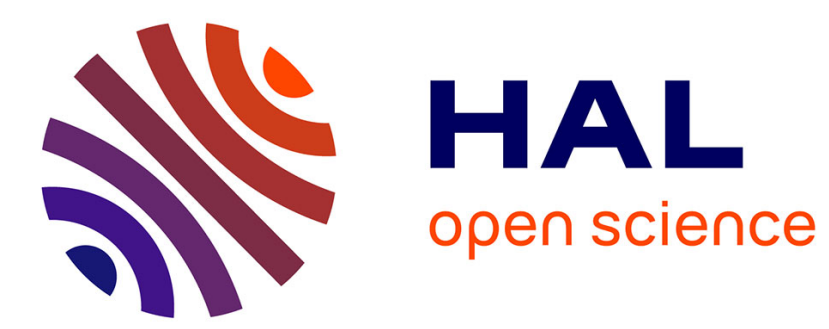

\title{
Spatio-temporal Reasoning by Combined Topological and Directional Relations Information
}

Nadeem Salamat, El-Hadi Zahzah

\section{To cite this version:}

Nadeem Salamat, El-Hadi Zahzah. Spatio-temporal Reasoning by Combined Topological and Directional Relations Information. 2011. hal-00551282

\section{HAL Id: hal-00551282 \\ https://hal.science/hal-00551282}

Preprint submitted on 6 Jan 2011

HAL is a multi-disciplinary open access archive for the deposit and dissemination of scientific research documents, whether they are published or not. The documents may come from teaching and research institutions in France or abroad, or from public or private research centers.
L'archive ouverte pluridisciplinaire HAL, est destinée au dépôt et à la diffusion de documents scientifiques de niveau recherche, publiés ou non, émanant des établissements d'enseignement et de recherche français ou étrangers, des laboratoires publics ou privés. 


\title{
Spatio-temporal Reasoning by Combined Topological and Directional Relations Information
}

\author{
Nadeem SALAMAT • El-hadi ZAHZAH
}

Received: date / Accepted: date

\begin{abstract}
Spatio-temporal reasoning is extensively used in many areas of computer vision and Artificial Intelligence. Different models for spatio-temporal reasoning are proposed based on topological and directional relations separately in respective domains. Reasoning about moving objects in a spatial scene or description about the two-dimensional scene needs both the reasoning systems simultaneously. We introduced a reasoning system of a two-dimensional spatial scene based on Combined Topological and Directional(CTD) relations method, where we obtain both topological and orientation information simultaneously. Entities in composite tables follows the certain mathematical rule, these rules are elaborated through the certain examples and the composition table for topological relations are rearranged and divided into sub-tables.

Key words:Spatio-temporal reasoning, combined topological and directional relations, .
\end{abstract}

\section{Introduction}

Common sense knowledge representation is the qualitative and it is shown that qualitative knowledge represents the superset of the quantitative knowledge [12]. Spatial knowledge has a central point in many domains like Artificial Intelligence (AI), spatio-temporal reasoning, natural language processing, human machine interaction, automated reasoning. Spatio-temporal reasoning plays an important role in many computer vision applications, such as path planning in robotics, visual object recognition at higher level which includes the interpretation and integration of visual information and video scene interpretation.

Université de La Rochelle

Laboratoire de Mathématiques, Images et Applications

Avenue M Crépeau La Rochelle 17042, France

$\left\{\right.$ nsalam01* ${ }^{\star}$ ezahzah\}@univ-lr.fr 
Spatial knowledge representation takes into account the different aspects of space, which includes the topological, orientation, distance relations, shape and size information. Methods for topological reasoning are introduced like Region Connected Calculus (RCC) based approaches [2-4,11,28], fuzzy approaches $[1,14,27,17]$ and 9 -intersections method[5]. In most of the spatial knowledge representation techniques, knowledge about the topological and orientation relations is represented at different abstraction level and different frames of reference are used and two separate systems for reasoning about topological and directional knowledge are developed $[8,19,20]$ and a combined systems are developed in $[13,10,16]$.

The different objects in an image or a snapshot constitute a situation, which can be understood or described through relationship between the entities which constitute situation. When the objects change their relative position, they change the relative information like the distance between them, orientation or topological information. Topological transformation represents the different types of changes in spatial scene such as translation, uniform expansion or contraction of one object and tearing or shearing one object. Only translation topological transformation represent the relative movement. In this paper only translation is considered and it is supposed that the entities (objects) don't change the topological configuration, i. e., object is not splits into multiple objects. Under these conditions, translated object is considered as the moving object and a discrete motion is considered[9]. Most of the reasoning process is based on the composition tables, entities in these tables are interrelated and abide by a certain mathematical formula.

Combined Topological and Directional relations(CTD) method[23] uses the intrinsic frame of reference and both the type of relations are well-defined without generalizing the object geometry. The concept of orientation and topological information are integrated into the single model. It is observed that each technique is domain based and was developed a separate system for reasoning about topological or directional relations, in this paper we use CTD method, which is domain independent and represents the topological and directional relations information at the same level of abstraction. This method combines the features of a direction calculi and a calculi of a binary topological relations. To make the paper self contained a small introduction of the CTD method is given.

This paper consist of following parts, section 2 explains the related work and section 3 explains the relevant terms which are frequently used in this paper. Combined topological and directional relations method is explained in section 4 , section 5 explains the neighborhood graph and change in spatial scene, section 6 explains the relation between the object pair and their converse relations section 7 composed on composition tables, in this section we explore the certain relation between the entities of the composition tables and observe that these tables can be improve from coarse knowledge to finer spatial knowledge by adding the orientation information into topological relations composition tables and vice versa and section 8 concludes the paper. 


\section{Related work}

Spatial reasoning attempt to represent the data in a linguistic variables, if the observers or human controllers are involved, linguistic variables are related to numeric or geometric representation. Spatial reasoning, especially computing the composition tables for a relation can be done at a coarse information or finer levels depending on the kind of available information.

Numerous techniques has been introduced for spatial and spatio-temporal reasoning during the recent years. Fuzzy methods are among them and fuzzy topological relations based on nearness are used in [27] for fuzzy spatial reasoning. In this method, there are 144 general transitive rules are formed and reasoning is based on these rules, but this technique involve only the topological reasoning and the question about the orientation still remains unanswered.

There is a direct isomorphism between the physical structure of time and one-dimensional spatial structure. Allen[15] introduced thirteen mutually exclusive exhaustive interval relations. Nowadays these relations are used for modeling the directional and combined topological and directional relations information due to this isomorphism between the time structure and onedimensional space structure[21,24,23]. Topological and qualitative directional relations are combined in $[26,25]$. We used the Combined Topological and directional (CTD) relations method, presented in [23], for reasoning the topological and directional relations.

Our approach for reasoning about the space is inspired by the approach of representing the spatial knowledge adopted in $[13,16]$, where the spatial knowledge of projection and orientation for a two-dimensional scene is presented. Relative orientation for the inclusion case is also introduced, i. e., inclusion spatial relation is further explored and directional contents are also introduced for the topological relations TPP and TPPI. These cases are explored due to certain reasons like all objects included in the another can be manipulated by the parent objects. Describing the global scene, they can be relatively described with respect to parent object. For example, objects inside the room inherit the orientation of that room with respect to others in the building. But how can be objects described lying inside the room, i. e., what will be the orientation of objects inside room relative to the room?

As it is the change of knowledge representation through $R C C 5$ to $R C C 8$ in region connected calculus, where the inclusion spatial relation is further divided into four spatial relations, namely TPP, NTPP, TPPI, NTPPI. In such a case, the relations TPP, TPPI also have the directional or orientation contents. Two separate system of composition table are developed for topological and directional relations. Entities in these tables are interrelated through the certain mathematical rules. These rule are explained in section 7 . 


\section{Preliminary definitions}

In this section we recall some basic definitions which are frequently used throughout the reminder of the paper.

Fuzzy set: A fuzzy set $A$ in a set $X$ is a set of pairs $\left(X, \mu_{A}(x)\right)$ such that $A=\left\{\left(x, \mu_{A}(x) \mid x \in X\right)\right\}$

Fuzzy membership function: A membership function $\mu$ in a set $X$ is a function $\mu: X \rightarrow[0,1]$. Different fuzzy membership functions are proposed according to the requirements of the applications. For instance, Trapezoidal membership function is defined as

$$
\mu(x ; \alpha, \beta, \gamma, \delta)=\max \left(\min \left(\frac{x-\alpha}{\beta-\alpha}, 1, \frac{\delta-x}{\delta-\gamma}\right), 0\right)
$$

it is written as $\mu_{(\alpha, \beta, \gamma, \delta)}(x)$ where $x, \alpha, \beta, \gamma, \delta \in \mathbb{R} \wedge \alpha<\beta \leq \gamma<\delta$.

Converse of a relation: Let $R$ be a relation between the object pair $(A, B)$, written as $R(A, B)$, then its converse relation $\tilde{R}$ is a relation between the same object pair when objects commute. It is defined as

$$
\tilde{R}(A, B)=R(B, A)
$$

Transitivity: The composition $R_{1} \odot R_{2}$ of two general relations $R_{1}, R_{2}$ is a relation $R$ defined as

$$
R_{1}(A, B) \odot R_{2}(B, C) \Rightarrow R(A, C)
$$

where $(A, B, C)$ are three objects.

Conceptual neighbor: Two relations between pairs of events are (conceptual) neighbors, if they can be directly transformed into one another by continuously deforming (i. e. by shortening, lengthening or moving) events (in topological sense) and a set of relations between pair of events forms a conceptual neighborhood graph if its elements are path connected through conceptual neighbor relations[7].

Force histogram: The force histogram attaches a weight to the argument object $A$ that this lies after $B$ in direction $\theta$, it is defined as

$$
\mathbf{F}^{A B}(\theta)=\int_{-\infty}^{+\infty} F\left(\theta, A_{\theta}(v), B_{\theta}(v)\right) d v
$$

The definition of Force histogram $\mathbf{F}^{A B}(\theta)$, directly depends upon the definition of real valued functions $\phi, f$ and $F$ used for the treatment of points, segments and longitudinal sections respectively[18]. These functions are defined as 


$$
\left.\begin{array}{rl}
\phi_{r}(y) & = \begin{cases}\frac{1}{y^{r}} & \text { if } y>0 \\
0 & \text { otherwise }\end{cases} \\
f\left(x_{I}, y_{I J}^{\theta}, z_{J}\right) & \left.=\int_{x_{I}+y_{I J}^{\theta}}^{x_{I}+y_{I J}^{\theta}+z_{J}} \int_{0}^{z_{J}} \phi(u-w) d w\right) d u \\
F\left(\theta, A_{\theta}(v), B_{\theta}(v)\right) & =\sum_{i=1 . . n, j=1 . . m} f\left(x_{I i}, y_{I i J j}^{\theta}, z_{J j}\right)
\end{array}\right\}
$$

Where $n, m$ represents the number of segments of object $A$ and object $B$ respectively and variables $(\mathrm{x}, \mathrm{y}, \mathrm{z})$ are explained in figure 1 . These are the definitions of Force histograms, directly depending upon the definition of function $\phi . \mathbf{F}^{A B}(\theta)$ is actually a real valued function.

\section{Oriented lines and fuzzy Allen relations}

In this section, certain terms used for computations are explained. Drawing of oriented lines, segments and longitudinal sections are explained in subsection 4.1 and Allen relations in section 4.2. Combination of topological and directional relations are explained in section 4.3 and 4.4 .

\subsection{Oriented lines, segments and longitudinal sections}

$A$ and $B$ be two spatial objects and $(v, \theta) \in \mathbb{R}$, where $v$ is any real number and $\theta \in[0,2 \pi] . \Delta_{\theta}(v)$ is an oriented line at orientation angle $\theta$ and $A \cap \Delta_{\theta}(v)$ is the intersection of object $A$ and oriented line $\Delta_{\theta}(v)$. It is denoted by $A_{\theta}(v)$, called segment of object $A$ and length of its projection interval on x-axis is $x$. Similarly for object $B$ where $B \cap \Delta_{\theta}(v)=B_{\theta}(v)$ is segment and length of its projection interval on $\mathrm{x}$-axis is $z, y$ is the difference between minimum of projection points of $A \cap \Delta_{\theta}(v)$ and maximum value of projection points of $B \cap \Delta_{\theta}(v)$ (for details[21]). In case of polygonal object approximation $(x, y, z)$ can be calculated from intersecting points of line and object boundary, oriented lines are considered which passes through at least one vertex of two polygons. If there exist more than one segment, then it is called longitudinal section as in case of $A_{\theta}(v)$ in figure 1.

\subsection{Allen temporal relations in spatial domain and fuzziness}

Allen[15] introduced 13 jointly exhaustive and pairwise disjoint (JEPD) interval relations. These relations are $\mathcal{A}=\left\{<, m, o, s, f, d, e q, d_{i}, f_{i}, s_{i}, o_{i}, m_{i},>\right\}$ with meanings before, meet, overlap, start, finish, during, equal, during_by, finish by, start by, overlap by, meet by and after. Allen relations in space are conceptually illustrated in figure (2). 


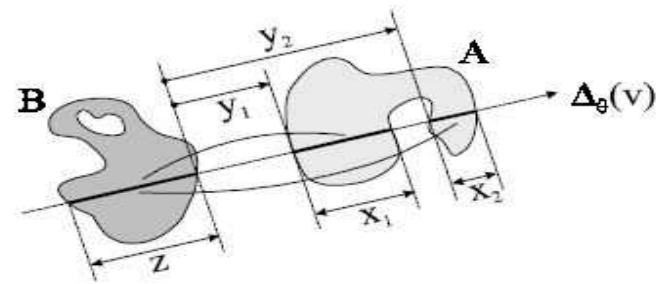

Fig. 1 Oriented line $\Delta_{\theta}(v)$, segment as in case of object $B$, longitudinal section as in case of object $A[21]$.

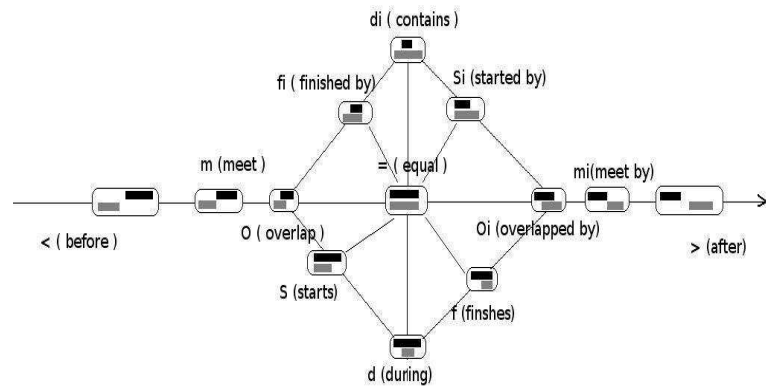

Fig. 2 Black segment represents the reference object and gray segment represents argument object

These relations have a rich support for the topological relations and represents the eight topological relations in one-dimensional spatial domain. Eight relations are possible combination of eight independent Allen relations in onedimensional spatial domain. Inverse of these relations and their reorientation represented in tables (1) and table (2). These tables show that whole twodimensional space can be explored with the help of one-dimensional Allen relations using oriented lines varying from $[0, \pi]$.

\begin{tabular}{|l||c|}
\hline Relation & Inverse \\
\hline$<$ & $>$ \\
$\mathrm{m}$ & $\mathrm{mi}$ \\
$\mathrm{o}$ & $\mathrm{oi}$ \\
$\mathrm{s}$ & $\mathrm{si}$ \\
$\mathrm{f}$ & $\mathrm{fi}$ \\
$\mathrm{d}$ & $\mathrm{di}$ \\
$=$ & $=$ \\
& \\
\hline
\end{tabular}

\begin{tabular}{|l||c|}
\hline Relation & Re-orientation \\
\hline$<$ & $>$ \\
$\mathrm{m}$ & $\mathrm{mi}$ \\
$\mathrm{o}$ & $\mathrm{oi}$ \\
$\mathrm{s}$ & $\mathrm{f}$ \\
$\mathrm{fi}$ & $\mathrm{si}$ \\
$\mathrm{d}$ & $\mathrm{d}$ \\
$\mathrm{di}$ & $\mathrm{di}$ \\
$=$ & $=$ \\
\hline
\end{tabular}

Table 1 Allen relations and their inverse Table 2 Allen relations and their reorienta-

Fuzzy Allen relations are used to represent the fuzzy topological relations where fuzziness is represented at the relation's level. Fuzzification process of 
Allen relations don't depend a fuzzy membership function. Trapezoidal membership function (equation (1)) is used due to flexibility in shape change.

Let $r(I, J)$ be an Allen relation between segments $I$ (Segment of an argument object) and $J$ (Segment of reference object), $r^{\prime}$ is the distance between $r(I, J)$ and it's conceptional neighborhood. We consider a fuzzy membership function $\mu: r^{\prime} \longrightarrow[0,1]$. The fuzzy Allen relations are defined in [26] as

$$
\begin{aligned}
f_{<}(I, J) & =\mu_{(-\infty,-\infty,-b-3 a / 2,-b-a)}(y) \\
f_{>}(I, J) & =\mu_{(0, a / 2, \infty, \infty)}(y) \\
f_{m}(I, J) & =\mu_{(-b-3 a / 2,-b-a,-b-a,-b-a / 2)}(y) \\
f_{m i}(I, J) & =\mu_{(-a / 2,0,0, a / 2)}(y) \\
f_{O}(I, J) & =\mu_{(-b-a,-b-a / 2,-b-a / 2,-b)}(y) \\
f_{O i}(I, J) & =\mu_{(-a,-a / 2,-a / 2,0)}(y) \\
f_{f}(I, J) & =\min \left(\mu_{(-(b+a) / 2,-a,-a,+\infty)}(y), \mu_{(-3 a / 2,-a,-a,-a / 2)}(y), \mu_{(-\infty,-\infty, z / 2, z)}(x)\right) \\
f_{f i}(I, J) & =\min \left(\mu_{-b-a / 2,-b,-b,-b+a / 2}(y), \mu_{(-\infty,-\infty,-b,-(b+a) / 2)}(y), \mu_{(z, 2 z,+\infty,+\infty)}(x)\right) \\
f_{s}(I, J) & =\min \left(\mu_{-b-a / 2,-b,-b,-b+a / 2}(y), \mu_{(-\infty,-\infty,-b,-(b+a) / 2)}(y), \mu_{(-\infty,-\infty, z / 2, z)}(x)\right) \\
f_{s i}(I, J) & =\min \left(\mu_{(-(b+a) / 2,-a,-a,+\infty)}(y), \mu_{(-3 a / 2,-a,-a,-a / 2)}(y), \mu_{(z, 2 z,+\infty,+\infty)}(x)\right) \\
f_{d}(I, J) & =\min \left(\mu_{(-b,-b+a / 2,-3 a / 2,-a)}(y), \mu_{(-\infty,-\infty, z / 2, z)}(x)\right) \\
f_{d i}(I, J) & =\min \left(\mu_{(-b,-b+a / 2,-3 a / 2,-a)}(y), \mu_{(z, 2 z,+\infty,+\infty)}(x)\right)
\end{aligned}
$$

where $a=\min (x, z), b=\max (x, z)$ and $x$ is the length of segment (I) and $z$ is the length of segment $(\mathrm{J})$ and $(\mathrm{x}, \mathrm{y}, \mathrm{z})$ are computed as described in section 4.1 .

Most of relations are defined by one membership function but some of them are defined by conjunction of more than one membership functions like $d($ during $), d_{i}$ (during_by), $f$ (finish), $f_{i}$ (finished_by). In fuzzy set theory, sum of all the relations is one, this gives the definition for fuzzy relation equal.

These are the topological relations which represent fuzziness at relation's level. For example, Meet topological relation is represented based on nearness and length of smaller interval defines the smooth transition between the Meet (Meet_by) and before (after) relation. In spatial domain, before (after) are called the disjoint topological relations.

\subsection{Combining topological and directional relations}

The approaches for topological relations between objects are developed largely by the Max.J. Egenhofer[6] using the point set topology. This relationship between two regions is represented by a $3 \times 3$ matrix, called 9-intersections model. There are eight topological relations. These eight topological relations are Disjoint, Meet, overlap, Covers, contain, Covered_by, Contained, Equal. It considers only one piece region without holes in two-dimensional space.

On the other hand, $R C C 8$ was developed by Randell et al.[22], an axiomatic theory which represents the topological relations. Relations in this 
theory are based on a single atomic relation connection. It represents the same eight topological relations between object pair with different names. Relations are $\{D C, E C, P O, T P P, N T P P, T P P I, N T P P I, E Q\}$, called respectively DisConnected, Externally Connected, Partially Overlap, Tangent Proper Part, Non Tangent Proper Part, Tangent Proper Part Inverse, Non Tangent Proper Part Inverse, Equal The difference of names is due to English language semantics ${ }^{1}$ otherwise both theories represent the same topological relations.

Allen's temporal relations in spatial domain represents the eight topological relations in one-dimensional space. We extend these Allen relations for the $2 D$ objects through the logical implication, where a two-dimensional object is decomposed into parallel segments of a $1 D$ lines in a given direction and the relation between each pair of line segments are computed. This method is called Combined Topological and Directional relations (CTD) method.

\subsection{CTD method}

The process of object decomposition is repeated for each direction varying from 0 to $\pi .2 D$ topological relations are defined as it provides us the information that how the objects are relatively distributed. Relations are represented as $\left(R_{T}, R_{D i r}\right)$, where $R_{T}$ stands for a topological relation such as $\{D, M, T P P$, NTPP, TPPI, NTPPI, EQ\} with meanings disjoint, meet, tangent proper part, non tangent proper part, tangent proper part inverse, non tangent Proper part inverse and equal. Similarly $R_{D i r}$ stands for directional relations between object pair such as $\{E, N E, N, N W, W, S W, S, S E\}$ with meanings east, north east, north, north west, west, south west, south and south east.

These relations are not Jointly Exhaustive and Pairwise Disjoint (JEPD). To obtain JEPD set of topological and directional relations an algorithm was advocated in [23], it provides us the JEPD set of relations. Objects are approximated through the polygon object approximation. Different steps of computing the combined topological and directional relations are

- Fix an angle $\theta$ and draw lines passing through the Vertices of polygons representing the objects. For this purpose, simple line drawing formula of slop intercept form can be used and intercepts can be computed from the Vertices of polygons.

- For each line compute variables $(x, y, z)$ and use mathematical equations given in section 4.2 to compute Allen relation, if there exist more than one segment, then use the fuzzy operators to integrate the information, usually the disjunction operators are suitable. These relations are computed for each line in a direction, then obtained information are integrated into a single value, then these relations are normalized for a given direction $\theta$ by dividing sum of all Allen relations to each Allen relation.

\footnotetext{
1 In $R C C$ "DC= Disconnected" and 9-intersections represent the "D=Disjoint" same semantics we use in our terminology " $\mathrm{D}$ " for disjoint topological relation, similarly for "M" for "meet".
} 
- These normalized value of a fuzzy Allen relation is then multiplied to a fuzzy directional set to find the degree of an Allen relation in a direction, at the last step

- To find the qualitative directions, these information are summarized and different topological relations with directional contents are defined as $f_{E}=$ $\sum_{\theta=0}^{\frac{\pi}{4}} \mathcal{A}_{r_{2}} \times \cos ^{2}(2 \theta)+\sum_{\theta=\frac{3 \pi}{4}}^{\pi} \mathcal{A}_{r_{1}} \times \cos ^{2}(2 \theta)$, where $f$ represents a topological relation and $E$ represents the direction.

- This information is represented in a matrix. Then a small algorithm is run which enables us to have a JEPD set of topological and directional relations. These relations for an object pair are represented in following example.

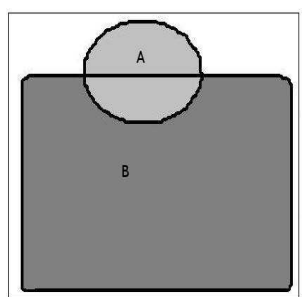

(a)

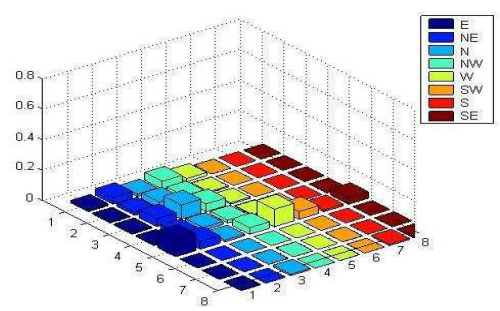

(b)

Fig. 3 Object pair and their combined topological and directional relation information qualitative topological and directional relations are $(P O, N)$

\section{Conceptual neighborhood graph and object change in spatial position}

In this section we will explain the possible changes in the topological and directional relations that is explained in section 5.1 and conceptual neighborhood graph for CTD method section 5.2 and continuity of spatial relations in section 5.3.

\subsection{Conceptual neighborhood graph and change in spatial relations}

In real world situations, spatial and temporal relationships between objects change continuous. The objects change its position to the next neighboring position. The continuous change in topological relations can be depicted as:

$$
D(A, B) \Rightarrow M(A, B) \Rightarrow P O(A, B) \Rightarrow T P P(A, B) \Rightarrow N T P P(A, B)
$$

The movement can be represented as change in directional relations,

$$
N(A, B) \Rightarrow N E(A, B) \Rightarrow E(A, B) \Rightarrow S E(A, B) \Rightarrow S(A, B) \Rightarrow . .
$$


Similarly for other topological and directional relations sequence of change in the spatial relations can be assessed. When these topological and directional relations are taken together, they might change the topological or directional part of the relation between two objects or both the topological and directional relations between objects. This change in spatial relation between two objects can be represented as a change in pair of relations. For better explanation let us consider the possible changes from the initial position of $(M(A, B), E(A, B))$ (called $A, B$ meets each other from East)

$$
(M(A, B), E(A, B)) \Rightarrow\left\{\begin{array}{lc}
(M(A, B), N E(A, B)) & \text { Change in directional relation } \\
(M(A, B), S E(A, B)) & \text { Change in directional relation } \\
(P O(A, B), N E(A, B)) & \begin{array}{c}
\text { Change in topological } \\
\text { and directional relation }
\end{array} \\
(P O(A, B), E(A, B)) & \begin{array}{c}
\text { Change in topological relation } \\
\text { Change in topological }
\end{array} \\
(P O(A, B), S E(A, B)) & \begin{array}{c}
\text { and directional relation } \\
\text { Change in topological }
\end{array} \\
(D(A, B), N E(A, B)) & \begin{array}{c}
\text { and directional relation } \\
\text { Change in topological relation } \\
(D(A, B), E(A, B))
\end{array} \\
(D(A, B), S E(A, B)) & \begin{array}{c}
\text { Change in topological } \\
\text { and directional relation }
\end{array}
\end{array}\right.
$$

The other possible transitions from one spatial position to the other can easily be derived. The whole transitions can be represented as a transition graph, where connected pairs of the spatial relations are called neighbors and this graph is called as the neighborhood graph. Neighborhood graph depicts the all physical transitions between spatial relations that can occur through the deformation of intervals.

Three types of interval deformation are identified called A-deformation, B-deformation and C-deformation [7]. A-deformation occurs when the one interval expands or contracts with one point fixed, i. e., one interval is stretched or shearing occurs. A deformation is called B-deformation when intervals don't change the size, only interval change their position with time. $\mathbf{C}$-deformation is characterized as the uniform expansion or contraction of interval take place. We represent here only one possible transition from partially overlap relation.

\subsection{Conceptual neighborhood and neighborhood graph}

Neighbor graph of topological relations represent three types of topological deformations. Here for simplicity of graph, only one branch of $\mathbf{B}$-deformation is taken into account and possible transitions are presented into the graph. In figure 4, object can move to a circular path,orientation neighborhood and straightened path, a topological neighborhood, beside these paths there is another path called diagonal path, in this a case object moves towards the topological and orientation neighborhood. 


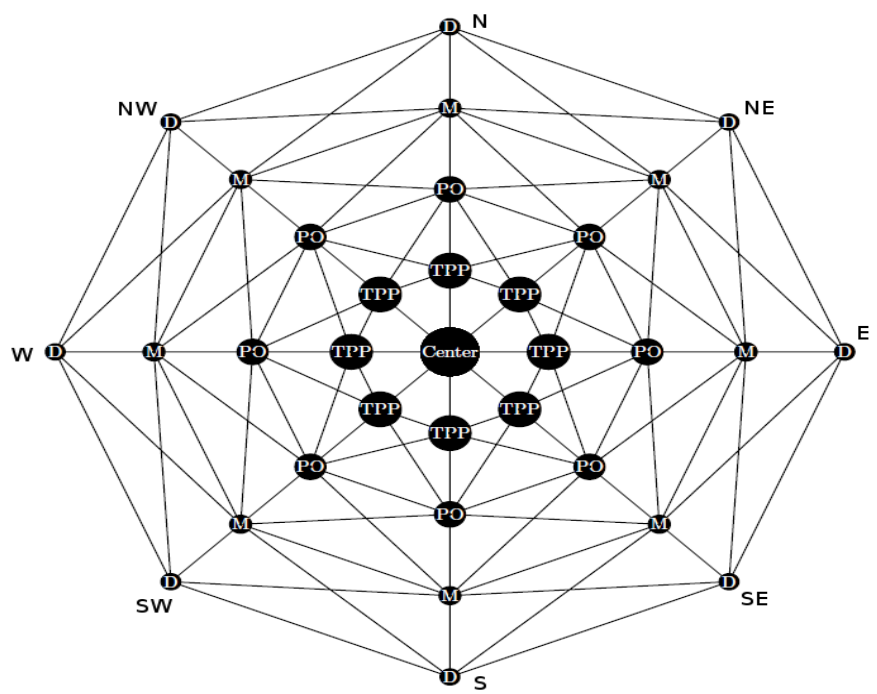

Fig. 4 Neighborhood graph in the system of combined topological and directional relations

Neighborhood graph shows the allowable transitions among the relations, these transitions are possible when the objects move or change occurs in a spatial scene. In figure 4 , it is shown that every point of a neighborhood graph has eight possible direction nodes. Here relations are represented by a pair $\left(R_{T}, R_{D i r}\right)$ where $R_{T}$ represents the topological relation and $R_{D i r}$ represents the orientation relation between the object pair.

\subsection{Conceptual neighborhood graph and continuity}

Continuity in motion is modeled as a continuous change in the spatial relations. In neighborhood graph two connective nodes represents two states of moving objects and the edge between them represent the time. Let us consider that $(0,0)$ shows the position of a node and +1 shows the possible movement of a relation and -1 shows the possible movement of the relation in opposite direction. When the topological relation is in outermost shell, then topological change is not possible in outward direction, as a result, in outward direction, object change the distance relation or distance and directional relation at the same time.

For example if $(0,0)$ position shows the relation $(E C, E)$, then -1 in topological neighborhood may represent the $P O$ (respectively $D$ ) then 1 represents the $D$ (respectively $P O$ ) similarly -1 in directional neighborhood may represent the directional relation $N E$ (respectively $S E$ ) then 1 will represent the relation $S E$ (respectively $N E$ ). Similar rule applies for the diagonal neighborhood. If the objects have the $E Q$ spatial relations then shell representing the relation TPP/TPPI disappears and NTPP, NTPPI relation is replaced with the relation $E Q$. 


\section{Topological and directional relations and their converse}

This system provides the topological and directional relations at the same abstraction level. If $R$ defines relation between object pair $(A, B), R$ has two components, first component is the topological component and provide us information about the topological relation between objects and second component provide us information about the angular order between object pair. Formally this can be written as

$$
R(A, B)=\left(R_{T}(A, B), R_{D i r}(A, B)\right)
$$

where $R_{T}, R_{\text {Dir }}$ represents the topological and directional parts respectively and converse relation (recall equation 2). $R(A, B)$ has two components (equation 6) and each component acts independently, its topological part has the topological converse and converse of a directional part commutes with the symmetric properties of the angular order. i. e.,

$$
R(A, B)=\left(R_{T}(A, B), R_{D i r}(A, B)\right)
$$

and its symmetric properties for directional relations are

$$
R_{D i r}(B, A)=R_{D i r}(A, B)+\pi
$$

By combining the equation 6, 7 and 8, The converse relation (equation 2) can be rewritten for this system as

$$
\tilde{R}(A, B)=\left(\tilde{R}_{T}(B, A), R_{D i r}(A, B)+\pi\right)
$$

The table3 represents converse of all the topological relations in the twodirectional space. This table shows that most topological relations have the same converse relation, i. e., topological relation doesn't depend on the order of objects. The table4 shows the converse of directional relations. These

\begin{tabular}{|c|c|c|c|}
\hline Topological relation $\left(R_{T}\right)$ & Symbol & Converse topological relation $\left(R_{T}\right)$ & Symbol \\
\hline \hline Disjoint & D & Disjoint & D \\
\hline Meet & EC & Meet & EC \\
\hline Partially overlap & PO & Partially overlap & PO \\
\hline Tangent proper part & TPP & Tangent proper part inverse & TPPI \\
\hline Non tangent proper part & NTPP & Non tangent proper part inverse & NTPPI \\
\hline Tangent proper part inverse & TPPI & Tangent proper part & TPP \\
\hline Non tangent proper part inverse & NTPPI & Non tangent proper part & NTPP \\
\hline Equal & Eq & Equal & EQ \\
\hline
\end{tabular}

Table 3 Topological relations and their converse

relations have a difference $\pi$ with their converses. 


\begin{tabular}{|c|c|c|c|}
\hline Directional relation $\left(R_{\text {Dir }}\right)$ & Symbol & Converse dir relation $\left(\tilde{R}_{\text {Dir }}\right)$ & Symbol \\
\hline \hline East & $\mathrm{E}$ & West & $\mathrm{W}$ \\
\hline North_East & $\mathrm{NE}$ & South_west & $\mathrm{SW}$ \\
\hline North & $\mathrm{N}$ & South & $\mathrm{S}$ \\
\hline North_West & $\mathrm{NW}$ & South_East & $\mathrm{SE}$ \\
\hline West & $\mathrm{W}$ & East & $\mathrm{E}$ \\
\hline South_West & $\mathrm{SW}$ & North_East & $\mathrm{NE}$ \\
\hline South & $\mathrm{S}$ & North & $\mathrm{N}$ \\
\hline South_East & $\mathrm{SE}$ & North_West & $\mathrm{NW}$ \\
\hline
\end{tabular}

Table 4 Directional relations and their converse

\section{Composition tables}

Composition tables play important role in the spatio-temporal reasoning. These tables provide information that which spatial or topological relation is possible between the two objects at next time point. Language of CTD method, consists of individual variables called regions, represents the 43 predicates, hence there exist a table with $1849(43 \times 43)$ entries. It is a huge table and difficult to analyze and both topological and orientation knowledge are not interconnected, due to this reason, we decompose this table into multiple sub-tables. A transitivity table shows constraint that are satisfied by the spatial reasoning algorithm.

\subsection{Composition table for relations independent from directions}

First we compute the composition table for those topological relations where directions are not involved.

\begin{tabular}{|l||cc|c|c|}
\hline & \multicolumn{2}{||}{ NTPP } & NTPPI & EQ \\
\hline \hline NTPP & \multicolumn{2}{|c|}{ NTPP } & No info. & NTPP \\
\hline NTPPI & $\begin{array}{c}\text { PO } \\
\text { TPPI }\end{array}$ & TPPTPP & NTPPI & NTPPI \\
\hline EQ & \multicolumn{2}{|c|}{ NTPP } & NTPPI & EQ \\
\hline
\end{tabular}

Table 5 Composition table where no directional relation is involved

It is almost (table5) a symmetric table with one exception, that is when relation between one pair of objects is NTPP and the other pair has the topological relation NTPPI. This table shows that when on one side a topological relation is NTPPI and on the other side it is NTPP, all the topological relations are possible, in other words we have no information ${ }^{2}$. In such a case, table provides us no information, this involves some topological relations which have directional contents.

2 All the relations are possible and the result is not informative. In tables this relation is written as No info. 
7.2 Composition table when one object pair involves directional contents

\begin{tabular}{|l||c|c|c|c|c|}
\hline & D & EC & PO & TPP & TPPI \\
\hline \hline NTPP & D & D & $\begin{array}{c}\text { D,EC,PO, } \\
\text { TPP, NTPP }\end{array}$ & NTPP & No info. \\
\hline NTPPI & $\begin{array}{c}\text { D,EC, PO, } \\
\text { TPPI, NTPPI }\end{array}$ & $\begin{array}{c}\text { PO,TPPI, } \\
\text { NTPPI }\end{array}$ & $\begin{array}{c}\text { PO, TPPI, } \\
\text { NTPPI }\end{array}$ & $\begin{array}{c}\text { PO, TPPI, } \\
\text { NTPPI }\end{array}$ & NTPPI \\
\hline EQ & D & EC & PO & TPP & NTPPI \\
\hline
\end{tabular}

Table 6 Composition table when the relation in $B, C$ involves directions

\begin{tabular}{|l||c|c|c|}
\hline & NTPP & NTPPI & EQ \\
\hline \hline D & D,EC,PO,TPP,NTPP & D & D \\
\hline EC & PO,TPP,NTPP & D & EC \\
\hline PO & PO,TPP,NTPP & D,EC,PO,TPPI, NTPPI & PO \\
\hline TPP & NTPP & D,EC,PO,TPPI, NTPPI & TPP \\
\hline TPPI & PO,TPP,NTPP & NTPPI & TPPI \\
\hline
\end{tabular}

Table 7 Composition table when the relation in $A, B$ involves directions

Some observations can be made based on these composition tables. In this study first we fixe one type of a relation then find the possibilities for the other. Here first we fix the angular order relation for example $N$, then we build a composition table for the possible topological relations between objects $(A, C)$. In this table $E Q$ topological relation is not computed because it is an idempotent relation.

\begin{tabular}{|c|c|c|c|c|c|}
\hline & $\mathrm{D}$ & $\mathrm{EC}$ & PO & TPP & TPPा \\
\hline D & No info. & $\begin{array}{c}\text { D,EC, } \\
\text { PO,TPP, } \\
\text { NTPP }\end{array}$ & $\begin{array}{c}\text { D,EC, } \\
\text { PO,TPP, } \\
\text { NTPP }\end{array}$ & $\begin{array}{c}\text { D,EC, } \\
\text { PO,TPP, } \\
\text { NTPP }\end{array}$ & D \\
\hline $\mathrm{EC}$ & $\begin{array}{c}\text { D,EC, } \\
\text { PO,TPPI, } \\
\text { NTPPI }\end{array}$ & $\begin{array}{l}\text { D,EC, } \\
\text { PO, TPP, } \\
\text { TPPI,EQ }\end{array}$ & $\begin{array}{l}\text { D,EC, } \\
\text { PO,TPP, } \\
\text { NTPP }\end{array}$ & $\begin{array}{c}\text { EC, PO, } \\
\text { TPP, NTPP }\end{array}$ & $\mathrm{D}, \mathrm{EC}$ \\
\hline $\mathrm{PO}$ & $\begin{array}{c}\text { D, EC, } \\
\text { PO, TPPI, } \\
\text { NTPPI }\end{array}$ & $\begin{array}{c}\text { D,EC, } \\
\text { PO,TPPI, } \\
\text { NTPPI }\end{array}$ & No info. & $\begin{array}{l}\text { PO, TPP, } \\
\text { NTPP }\end{array}$ & $\begin{array}{c}\text { D,EC, } \\
\text { PO, TPPI, } \\
\text { NTPPI }\end{array}$ \\
\hline TPP & 171111 & $\mathrm{D}, \mathrm{EC}$ & $\begin{array}{c}\text { D,EC, } \\
\text { PO,TPP, } \\
\text { NTPP }\end{array}$ & TPP,NTPP & $\begin{array}{c}\text { D,EC, } \\
\text { PO,TPP, } \\
\text { TPPI, EQ }\end{array}$ \\
\hline TPPI & $\begin{array}{c}\text { D,EC, } \\
\text { PO, TPPI, } \\
\text { NTPPI }\end{array}$ & $\begin{array}{l}\text { EC,PO, } \\
\text { TPPI, } \\
\text { NTPPI }\end{array}$ & $\begin{array}{l}\text { PO, TPP, } \\
\text { NTPP }\end{array}$ & $\mathrm{PO}$ & $\begin{array}{l}\text { TPPI, } \\
\text { NTPPI }\end{array}$ \\
\hline
\end{tabular}

Table 8 Composition table for topological relations when both relations involves directions

We can define some composition rules based on these tables 
1. If the relation between object pairs are changed along with order, then resulting relation remains the same, i. e., if $R$ is a topological relation between object pair $(A, B)$ and $\tilde{R}$ is the relation between the object pair $(B, A)$, topological inverse, then composition will be

$$
R_{1}(A, B) \odot R_{2}(B, C)=R_{3}(A, C)
$$

and

$$
\tilde{R}_{2}(A, B) \odot \tilde{R}_{1}(B, C)=\tilde{R}_{3}(A, C)
$$

2. This table has the 21 different entries, out of 64 , these 21 entries have a certain relation and can be computed through the above cited relation, i. e.,

$$
R_{1}(A, B) \odot R_{2}(B, C)=R(A, C) \Rightarrow \tilde{R}_{2}(A, B) \odot \tilde{R}_{1}(B, C)=\tilde{R}(A, C)
$$

These relations can be expressed as shown below.
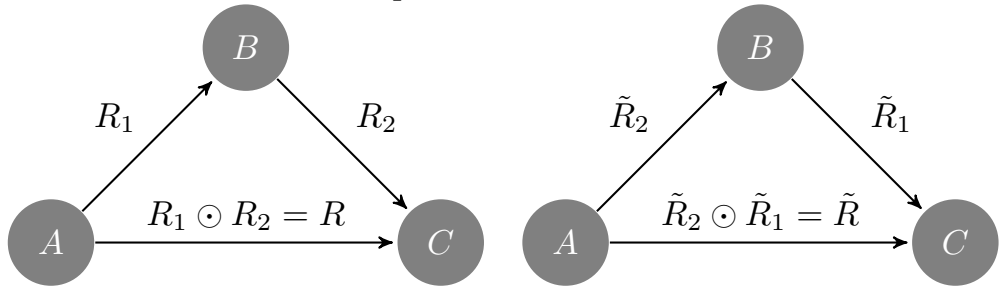

3. Equal relation is an identity element, it does not effect the composition of a topological relation. If inverse topological relations are involved in the composition table, then all the topological relations are possible and we have no information.

4. Composition relations are always in topological neighbors.

These tables represent the coarse knowledge disjunction. This derived knowledge can further be refined through the introduction of a directional contents between the object pair.

\subsection{Composition table for directional relations}

Table10 represents the composition table for directional relations. This composition table can be refined by introducing the topological relations.

A general rule can be followed that if the neighboring direction and same topological relation, then topological relation will be changed. If they have opposite or perpendicular direction, then topological relation between object pair remains same. 


\begin{tabular}{|c|c|c|c|c|c|c|c|}
\hline 7 & $D$ & $\mathrm{EC}$ & $\mathrm{PO}$ & TPP & NTPP & II TPPI & NTPPI \\
\hline D & No info. & $\begin{array}{l}\text { D,EC, } \\
\text { PO, } \\
\text { TPP, } \\
\text { NTPP }\end{array}$ & $\begin{array}{l}\text { D,EC, } \\
\text { PO, } \\
\text { TPP, } \\
\text { NTPP }\end{array}$ & $\begin{array}{l}\text { D,EC, } \\
\text { PO, } \\
\text { TPP, } \\
\text { NTPP }\end{array}$ & $\begin{array}{l}\text { D,EC, } \\
\text { PO, } \\
\text { TPP, } \\
\text { NTPP }\end{array}$ & D & 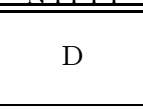 \\
\hline $\mathrm{EC}$ & $\begin{array}{l}\text { D,EC, } \\
\text { PO, } \\
\text { TPPI, } \\
\text { NTPPI }\end{array}$ & $\begin{array}{c}\text { D,EC, } \\
\text { PO, } \\
\text { TPP, } \\
\text { TPPI, } \\
\text { EQ }\end{array}$ & $\begin{array}{c}\text { D,EC, } \\
\text { PO, } \\
\text { TPP, } \\
\text { NTPP }\end{array}$ & $\begin{array}{c}\text { EC, PO, } \\
\text { TPP, } \\
\text { NTPP }\end{array}$ & $\begin{array}{l}\mathrm{PO}, \\
\text { TPP, } \\
\text { NTPP }\end{array}$ & $\mathrm{D}, \mathrm{EC}$ & D \\
\hline $\mathrm{PO}$ & $\begin{array}{c}\text { D,EC, } \\
\text { PO, } \\
\text { TPPI, } \\
\text { NTPPI } \\
\end{array}$ & $\begin{array}{c}\text { D,EC, } \\
\text { PO, } \\
\text { TPPI, } \\
\text { NTPPI }\end{array}$ & No info. & $\begin{array}{c}\text { PO, } \\
\text { TPP } \\
\text { NTPP }\end{array}$ & $\begin{array}{c}\mathrm{PO}, \\
\text { TPP } \\
\text { NTPP }\end{array}$ & \begin{tabular}{|c|} 
D,EC, \\
PO, \\
TPPI, \\
NTPPI
\end{tabular} & $\begin{array}{l}\text { D,EC, } \\
\text { PO, } \\
\text { TPPI, } \\
\text { NTPPI }\end{array}$ \\
\hline TPP & D & $\mathrm{D}, \mathrm{EC}$ & $\begin{array}{l}\text { D,EC, } \\
\text { PO, } \\
\text { TPP, } \\
\text { NTPP }\end{array}$ & TPP,NTPP & NTPP & $\begin{array}{c}\text { D,EC, } \\
\text { PO, } \\
\text { TPP, } \\
\text { TPPI, } \\
\text { EQ }\end{array}$ & $\begin{array}{l}\text { D,EC, } \\
\text { PO, }\end{array}$ \\
\hline NTPP & D & D & $\begin{array}{l}\text { D,EC, } \\
\text { PO, } \\
\text { TPP, } \\
\text { NTPP }\end{array}$ & NTPP & NTPP & $\begin{array}{l}\text { D, } \\
\text { EC, } \\
\text { PO, }\end{array}$ & No info. \\
\hline TPPI & $\begin{array}{c}\text { D, } \\
\text { EC, } \\
\text { POP, } \\
\text { TPPI, } \\
\text { NTPPI }\end{array}$ & $\begin{array}{c}\text { EC, } \\
\text { PO, } \\
\text { TPPI, } \\
\text { NTPPI }\end{array}$ & $\begin{array}{c}\text { PO,TPPI, } \\
\text { NTPPI }\end{array}$ & $\mathrm{PO}$ & $\begin{array}{l}\text { PO, } \\
\text { TPP, } \\
\text { NTPP }\end{array}$ & $\begin{array}{l}\text { TPPI, } \\
\text { NTPPI }\end{array}$ & NTPPI \\
\hline NTPPI & $\begin{array}{l}\text { D,EC, } \\
\text { POO, } \\
\text { TPPI, } \\
\text { NTPPI }\end{array}$ & $\begin{array}{l}\text { PO,TPPI, } \\
\text { NTPPI }\end{array}$ & $\begin{array}{c}\text { PO, } \\
\text { TPPI, } \\
\text { NTPPI }\end{array}$ & $\begin{array}{c}\text { PO, } \\
\text { TPPI, } \\
\text { NTPPI }\end{array}$ & $\begin{array}{c}\text { PO, } \\
\text { TPP } \\
\text { NTPP, } \\
\text { TPPP } \\
\text { NTPPI, } \\
\text { EQ }\end{array}$ & NTPPI & NTPPI \\
\hline
\end{tabular}

Table 9 Composition table for topological relations when both relations involve directions

\begin{tabular}{|c|c|c|c|c|c|c|c|c|}
\hline & $\mathrm{E}$ & $\mathrm{NE}$ & $\mathrm{N}$ & $\mathrm{NW}$ & W & SW & $S$ & $\mathrm{SE}$ \\
\hline $\mathrm{E}$ & $\mathrm{E}$ & $\mathrm{E}, \mathrm{NE}$ & $\begin{array}{c}\mathrm{E}, \mathrm{NE}, \\
\mathrm{N}\end{array}$ & $\begin{array}{l}\text { E,NE, } \\
\text { N, NW }\end{array}$ & No info. & $\begin{array}{l}\mathrm{SW}, \mathrm{S}, \\
\mathrm{SE}, \mathrm{E}\end{array}$ & $\begin{array}{c}\mathrm{E}, \mathrm{SE}, \\
\mathrm{S}\end{array}$ & E,SE \\
\hline $\mathrm{NE}$ & $\mathrm{E}, \mathrm{NE}$ & $\mathrm{NE}$ & $\mathrm{NE}, \mathrm{N}$ & $\begin{array}{c}\text { NE,N, } \\
\text { NW }\end{array}$ & $\begin{array}{c}\mathrm{NE}, \\
\text { N, } \\
\mathrm{NW}, \mathrm{W}\end{array}$ & No info. & $\begin{array}{c}\text { E,NE, } \\
\text { SE,S }\end{array}$ & $\begin{array}{c}\text { E,NE, } \\
\text { SE }\end{array}$ \\
\hline $\mathrm{N}$ & $\underset{N}{\mathrm{E}, \mathrm{NE}}$ & $\mathrm{NE}, \mathrm{N}$ & $\mathrm{N}$ & $\mathrm{N}, \mathrm{NW}$ & $\begin{array}{c}\mathrm{N}, \mathrm{NW} \\
\mathrm{W}\end{array}$ & $\begin{array}{l}\mathrm{N}, \mathrm{NW} \\
\mathrm{W}, \mathrm{SW}\end{array}$ & No info. & $\begin{array}{c}\mathrm{N}, \mathrm{NE}, \\
\mathrm{E}, \mathrm{SE}\end{array}$ \\
\hline NW & $\begin{array}{l}\text { E,NE, } \\
\text { N,NW }\end{array}$ & $\begin{array}{l}\text { NE,N, } \\
\text { NW }\end{array}$ & $\mathrm{N}, \mathrm{NW}$ & NW & $\mathrm{W}, \mathrm{NW}$ & $\begin{array}{c}\mathrm{NW}, \mathrm{W}, \\
\text { SW }\end{array}$ & $\begin{array}{l}\mathrm{NW}, \mathrm{W}, \\
\text { SW,S }\end{array}$ & No info. \\
\hline SW & $\begin{array}{l}\text { E,SE,S, } \\
\text { SW }\end{array}$ & No info. & $\begin{array}{l}\mathrm{N}, \mathrm{NW}, \\
\mathrm{W}, \mathrm{SW}\end{array}$ & $\begin{array}{c}\mathrm{NW}, \mathrm{W}, \\
\text { SW }\end{array}$ & W, SW & SW & SW,S & $\begin{array}{c}\text { SW,S, } \\
\text { SE }\end{array}$ \\
\hline S & $\begin{array}{c}\text { S,SE, } \\
\text { E }\end{array}$ & $\begin{array}{c}\text { NE,E, } \\
\text { SE,S }\end{array}$ & No info. & $\begin{array}{l}\text { NW,W, } \\
\text { SW,S }\end{array}$ & $\begin{array}{c}\text { W, } \\
\text { SW,S }\end{array}$ & S,SW & $\mathrm{S}$ & $\mathrm{S}, \mathrm{SE}$ \\
\hline $\mathrm{SE}$ & E,SE & $\begin{array}{c}\mathrm{NE}, \mathrm{E} \\
\mathrm{SE}\end{array}$ & $\begin{array}{c}\mathrm{N}, \mathrm{NE}, \\
\mathrm{E}, \mathrm{SE}\end{array}$ & No info. & $\begin{array}{l}\text { W,SW } \\
\text { S,SE }\end{array}$ & $\begin{array}{c}\text { SW,S, } \\
\text { SE }\end{array}$ & $\mathrm{S}, \mathrm{SE}$ & $\mathrm{SE}$ \\
\hline
\end{tabular}

Table 10 Composition table between directional relations when topological relations remains same

\section{Conclusion}

Spatio-temporal reasoning is an important part of the Artificial Intelligence and many applications in related fields, existing approaches in this field are domain based. The disjunction of relations represent the coarse knowledge and these information could be refined by adding the topological information to the composition table for directional relations and vice versa. Different 
techniques have been developed for reasoning the topological relations and no such a well defined technique could be found regarding the directional relations. Continuous moving objects can change the topological or directional or both the relations simultaneously. In this paper we used the method for CTD relations for reasoning which leads from the coarse knowledge to the finer knowledge of the spatial domain and this method represents the fuzziness at relations level. We established that the certain entities of the composition tables are interrelated and they follow the mathematical rule. This rule is generalized and composition table is rearranged and divided into sub-tables.

\section{References}

1. Bao, L., Qin, X., Zhang, J., Li, Q.Y.: Reasoning the spatiotemporal relations between time evolving indeterminate regions. In: ICMLC, pp. 448-458 (2005)

2. Cohn, A.G., Bennett, B., Gooday, J., Gotts, N.: RCC: a calculus for region-based qualitative spatial reasoning. GeoInformatica 1, 275-316 (1997)

3. Cohn, A.G., Gooday, J.M., Bennett, B.: A comparison of structures in spatial and temporal logics. In: R. Casati, B. Smith, G. White (eds.) Philosophy and the Cognitive Sciences: Proceedings of the 16th International Wittgenstein Symposium. HölderPichler-Tempsky, Vienna (1994)

4. Cohn, A.G., Renz, J.: Qualitative spatial reasoning. In: F. van Harmelen, V. Lifschitz, B. Porter (eds.) Handbook of Knowledge Representation. Elsevier (2007)

5. Egenhofer, M.J., Al-Taha, K.K.: Reasoning about Gradual Changes of Topological Relationships. In: Proceedings of the International Conference On GIS - From Space to Territory, pp. 196-219. Springer-Verlag, London, UK (1992)

6. Egenhofer, M.J., Franzosa, R.D.: Point Set Topological Relations . International Journal of Geographical Information Systems 5(2), 161-174 (1991)

7. Freksa, C.: Temporal Reasoning Based on Semi-intervals. Artif. Intell. 54(1-2), 199-227 (1992). DOI http://dx.doi.org/10.1016/0004-3702(92)90090-K

8. Freksa, C., München, T.U., Allen, .L.: Conceptual neighborhood and its role in temporal and spatial reasoning (1991)

9. Galton, A.: A generalized topological view of motion in discrete space. Theor. Comput. Sci. 305(1-3), 111-134 (2003). DOI http://dx.doi.org/10.1016/S0304-3975(02)00701-6

10. Galton, A.: Spatial and Temporal Knowledge Representation. Journal of Earth Science Informatics 2(3), 169-187 (2009). DOI DOI 10.1007/s12145-009-0027-6

11. Gotts, N., Gooday, J., Cohn, A.: A connection based approach to commonsense topological description and reasoning (1995)

12. Guesgen, H.: Spatial reasoning based on Allen's temporal logic (1989)

13. Hernández, D.: Relative representation of spatial knowledge: The 2-d case (1991)

14. Homaifar, E.D., Esterline, A.C., Dozier, G., Homaifar, A.: Fuzzy spatial reasoning. In: Proc. of the 1997 Int. Fuzzy Systems Association Conf (1997)

15. J.F., A.: Maintaining Knowledge about Temporal Intervals . Communications of the ACM 26(11), 832-843 (1983)

16. Li, S., Cohn, A.G.: Reasoning with topological and directional spatial information. CoRR abs/0909.0122 (2009)

17. Li, Y., Li, S.: A fuzzy sets theoretic approach to approximate spatial reasoning. Fuzzy Systems, IEEE Transactions on 12(6), 745 - 754 (2004)

18. Matsakis, P., Wendling, L.: A New Way to Represent the Relative Position between Areal Objects. IEEE Transactions on Pattern Analysis and Machine Intelligence 21(7), 634-643 (1999). DOI http://doi.ieeecomputersociety.org/10.1109/34.777374

19. Muller, P.: Topological spatio-temporal reasoning and representation. Computational Intelligence 18(3), 420-450 (2002)

20. Museros, L., Escrig, M.T.: Modeling motion by the integration of topology and time. Journal of Universal Computer Science. September Issue 9 (2003) 
21. P.Matsakis, Nikitenko, D.: Combined Extraction of Directional and Topological Relationship Information from 2D Concave Objects, in Fuzzy Modeling with Spatial Information for Geographic Problems. Springer-Verlag Publications, pp. 15-40, New York (2005)

22. Randell, D., Cui, Z., Cohn, A.: A spatial logic based on regions and connection. In: Proc. 3rd Int. Conf. on Knowledge Representation and Reasoning, pp. 165-176. Morgan Kaufmann, San Mateo (1992)

23. Salamat, N., Zahzah, E.: 2d fuzzy spatial relations: New way of computing and representation. submitted

24. Salamat, N., Zahzah, E.: On the improvement of combined topological and directional relations information. submitted

25. Salamat, N., Zahzah, E.: Fusion of fuzzy spatial relations. In: proceedings of The 5th International Conference on Hybrid Artificial Intelligence Systems (HAIS (1)), pp. 294$301(2010)$

26. Salamat, N., Zahzah, E.: Fuzzy spatial relations for 2 d scene. In: proceedings of The 2010 International Conference on Image Processing, Computer Vision, and Pattern Recognition (IPCV-10), pp. 47-53 (2010)

27. Schockaert, S., Cock, M.D., Kerre, E.E.: Spatial reasoning in a fuzzy region connection calculus. Artif. Intell. 173(2), 258-298 (2009)

28. Wolter, F., Zakharyaschev, M.: Spatio-temporal representation and reasoning based on rcc-8. In: In Proceedings of the seventh Conference on Principles of Knowledge Representation and Reasoning, KR2000, pp. 3-14. Morgan Kaufmann (2000) 